\title{
ESTADO DA ARTE: \\ A Integração Curricular no Ensino Médio Integrado dos Institutos Federais
}

\author{
Lílian Gobbi Dutra Medeiros ${ }^{1}$ \\ Márcia de Souza Oliveira Paes Leme Alberto² \\ Léia Adriana da Silva Santiago ${ }^{3}$
}

\begin{abstract}
RESUMO
Este trabalho é resultado de uma pesquisa qualitativa do tipo estado da arte, que teve como objetivo entender as concepções de integração curricular em teses e dissertações, com foco no Ensino Médio Integrado (EMI) dos Institutos Federais (IFs). Foi realizada uma busca na Biblioteca Digital de Teses e Dissertações (BDTD), que resultou em 13 trabalhos analisados. Paralelamente, elaboramos o perfil desses pesquisadores por meio de uma consulta na plataforma Lattes. A pesquisa mostrou que os estudos sobre a integração curricular no âmbito do EMI dos IFs esbarram no distanciamento do que se quer para o EMI daquilo que se faz. É possível constatar a inquietação e preocupação com a temática, contudo as investigações não indicam sugestões práticas para a materialização do currículo integrado.
\end{abstract}

Palavras-chave: Integração curricular. Ensino Médio Integrado. Institutos Federais.

\section{STATE OF THE ART: CURRICULAR INTEGRATION IN INTEGRATED HIGH SCHOOL OF FEDERAL INSTITUTES}

\section{ABSTRACT}

This paper is the result of a qualitative state-of-the-art research, which aimed to understand the concepts of curricular integration in theses and dissertations, focusing on integrated high school (IHS) of the Federal Institutes (FIs). A search at the Digital Library of Theses and Dissertations (DLTD) was conducted, which resulted in thirteen analyzed studies. In parallel, we elaborated the profile of these researchers, through a consultation on the Lattes platform. The research has shown that studies on curricular integration within the scope of the HIS of the Fls show the distancing of what is wanted for the IHS from what is done. It is possible to realize the concern with the theme, however the investigations do not point out practical suggestions for the materialization of the integrated curriculum.

Keywords: Curricular integration. Integrated high school. Federal Institutes.

Recebido em: 25/1/2020

Aceito em: 6/4/2020

\footnotetext{
${ }^{1}$ Licenciatura em Letras (Fundação Educacional de Ituiutaba, Universidade do Estado de Minas Gerais - UEMG, 2007). Especialização em Educação (Universidade Federal de Uberlândia). Mestranda do Programa de Educação Profissional e Tecnológica - ProfEPT (Instituto Federal de Educação, Ciência e Tecnologia Goiano - IF Goiano). Professora EBTT Português/Inglês - Ensino Básico, Técnico e Tecnológico (Instituto Federal do Triângulo Mineiro, campus Ituiutaba-MG). Tem atuação na área de Letras, com ênfase em Línguas Estrangeiras Modernas. http://lattes.cnpq.br/8246380702312165. https://orcid.org/0000-0001-6783-3101. liliandutra@iftm.edu.br

2 Graduação em Serviço Social pela Universidade Federal de Uberlândia. Experiência de estágio com adolescentes em cumprimento de Medidas Socioeducativas de Liberdade Assistida e Prestação de Serviço à Comunidade, atendidos pelo Creas do município de Ituiutaba/MG. Especialização em Instrumentalidade do Serviço Social pela Faculdade Única de Ipatinga-MG. Servidora pública no Instituto Federal do Triângulo Mineiro (setor de atendimento ao educando/psicossocial). http://orcid.org/0000-0003-4666-6732. http://orcid.org/0000-00034666-6732. marciapaes@iftm.edu.br

3 Mestrado em Educação pela Universidade Federal de Santa Catarina. Doutorado em Educação pela Universidade Federal do Paraná, com estágio pós-doutoral na Universidade Autônoma de Barcelona, Espanha (financiado pela Fundação Capes). Professora do Programa de Educação Profissional e Tecnológica - ProfEPT (Instituto Federal de Educação, Ciência e Tecnologia Goiano - IF Goiano) http://orcid.org/0000-0002-6057-6808. http://orcid.org/0000-0002-6057-6808. leia.adriana@ifgoiano.edu.br
} 
Instituídos pela Lei № 11.892 de 2008, os Institutos Federais (IFs) são instituições de ensino que têm como finalidade legal oferecer, entre outras modalidades e níveis, a educação técnica profissional. A rede dos IFs é constituída, desde a sua criação, pelos Institutos Federais de Educação, Ciência e Tecnologia, pela Universidade Tecnológica Federal do Paraná (UTFPR), pelos Centros Federais de Educação Tecnológica Celso Suckow da Fonseca (Cefet-RJ) e de Minas Gerais (Cefet-MG) e, a partir de 2012, pelas Escolas Técnicas Vinculadas às Universidades Federais e pelo Colégio Pedro II. De acordo com o Artigo 7으, inciso I, da referida Lei $\mathrm{n}$ - 11.892/2008, a rede deve, de maneira primaz, promover a educação profissional tecnológica de nível médio, priorizando sua oferta na forma de cursos integrados - Ensino Médio Integrado (EMI) - tanto para os jovens concluintes do Ensino Fundamental como na modalidade de Educação de Jovens e Adultos (EJA).

No que diz respeito à formação técnica profissional, o objetivo dos IFs é formar e qualificar "cidadãos com vistas à atuação profissional nos diversos setores da economia, com ênfase no desenvolvimento socioeconômico local, regional e nacional" (BRASIL, 2008). Além dessa formação mais voltada para o mundo do trabalho, o EMI ocupa-se também da formação geral, que subsidia a investidura do aluno em cursos superiores, por exemplo, assim como trabalha conhecimentos e saberes necessários para a atuação cidadã dos estudantes. As duas ideias de formação descritas nas linhas anteriores são esperadas para o EMI, seguindo a lógica da integração da formação técnica profissional e da formação geral, visando à formação de cidadãos capazes de superar a dicotomia trabalho manual e trabalho intelectual (MOURA, 2013). Dessa maneira, ao término do terceiro ano do EMI, o estudante pode tanto dar sequência aos estudos, num sentido de verticalização acadêmica, quanto iniciar-se no mercado de trabalho.

Essa formação integrada tem o objetivo futuro de contribuir para a superação da dualidade de classes, garantindo um padrão digno de vida e também de conhecimento, tanto para as elites quanto para os trabalhadores e seus filhos, que são os verdadeiros produtores da riqueza social (CIAVATTA, 2014). Assim, o que se quer evitar é a distinção entre a escola que forma líderes e gestores (historicamente caracterizada como a escola de qualidade que atende aos filhos da classe detentora dos meios de produção) e a escola que forma mão de obra para o mercado de trabalho (a escola para os filhos da classe trabalhadora).

Nesse sentido, o EMI deveria superar essa dualidade construída histórica e socialmente, por meio da integração do currículo das disciplinas gerais, a exemplo da Língua Portuguesa, História, Arte, Geografia, Matemática, entre outras, e as disciplinas profissionais, específicas de cada curso técnico. Essa formação é pautada nos conceitos de formação humana integral, omnilateral e politécnica ${ }^{4}$. Para esse fim, a organização curricular deve ser pensada de forma a romper com organização tradicional de justaposição de conteúdos, alocados em disciplinas isoladas. Segundo Moura (2012), a integração curricular deve ocorrer "de forma contínua ao longo da formação, sob os eixos

O termo politecnia, considerado reducionista por Nosella (2007), será por nós utilizado no sentido mais amplo da palavra, ao lado dos termos omnilateralidade e formação humana integral, que apontam para a formação dos sujeitos sob os ideais marxistas. 
do trabalho, da ciência, da tecnologia e da cultura" e pode se concretizar por meio de problemas, centros de interesses, projetos, complexos temáticos, investigação do meio, entre outras.

As Diretrizes Curriculares Nacionais para a Educação Profissional Técnica de Nível Médio (DCNEPTM) preveem uma

organização curricular flexível, por disciplinas ou componentes curriculares, projetos, núcleos temáticos ou outros critérios ou formas de organização, desde que compatíveis com os princípios da interdisciplinaridade, da contextualização e da integração entre teoria e prática, no processo de ensino e aprendizagem (BRASIL, 2012, p. 7).

Especificamente no universo do EMI, Moura (2012) entende que a integração total das disciplinas ou componentes curriculares seja algo relativamente impossível, devido à necessidade de aprofundamento de conteúdos científicos e tecnológicos próprios de suas respectivas unidades curriculares. O que ele sugere, portanto, é a organização do currículo por disciplinas com atividades integradoras, previstas e planejadas desde a formulação dos planos de cursos. Também deve ser levado em conta o pressuposto de que a integração curricular deve visar à educação com fins sociais e não simplesmente pedagógicos (ARAÚJO, 2014). Esse desenho estaria em consonância tanto com as DCNEPTM quanto com o propósito de formação integrada.

Nesse sentido, este estudo, do tipo estado da arte, teve o objetivo de entender as concepções de integração curricular em teses e dissertações, com foco no EMI dos IFs. Considerando o momento de criação dos IFs, relativamente recente do ponto de vista histórico no Brasil, ainda há muitos desafios e questionamentos em relação à materialização dessa integração do currículo. Assim, o EMI deve ser alvo frequente de investigação, o que justifica este estudo.

A escolha por pesquisar sobre o tema em trabalhos de conclusão de Mestrado e Doutorado e não, a princípio, em artigos, deu-se pelo fato de que as teses e dissertações defendidas em cursos de Pós-Graduação stricto sensu são frutos de pesquisas mais aprofundadas, considerando ainda o tempo dedicado ao tema. Quisemos, portanto, entender como as pesquisas brasileiras em programas de Mestrado e Doutorado têm abordado a temática da integração curricular, sobretudo tentando buscar estudos que trouxessem caminhos e ideias para que o currículo integrado no EMI dos IFs de fato assuma corporalidade.

Assim, nas linhas que se seguem, vamos apresentar os passos e procedimentos adotados no trabalho e os resultados obtidos em cada texto analisado.

\section{O CAMINHO METODOLÓGICO PERCORRIDO}

Para a construção deste estado da arte utilizamos a base de dados da Biblioteca Digital de Teses e Dissertações (BDTD). A justificativa da escolha da fonte assenta-se no fato de que a BDTD é uma plataforma ampla de acesso a teses e dissertações, com alimentação das principais universidades e instituições de cursos de Pós-Graduação do Brasil. 
Selecionamos como descritores "ensino médio integrado AND integração curricular AND instituto federal", com filtro no período de 2008 (quando da criação dos Institutos Federais) até o ano de 2019. Utilizamos o comando AND para que a pesquisa mostrasse apenas trabalhos que apresentassem, em qualquer lugar do texto, todas as expressões de interesse desta pesquisa, quais sejam "ensino médio", "integração curricular" e "instituto federal". Encontramos, nessa busca, um total de 45 resultados, dos quais 30 eram dissertações e 15 teses.

Em seguida, realizamos a análise dos trabalhos encontrados para a seleção dos textos de interesse da pesquisa. A partir dessa etapa, foram incluídos todos os trabalhos que apresentassem, no título e/ou no resumo, relação com o tema, independentemente da área de estudo. Foram excluídos estudos que não tivessem relação com a integração curricular em EMI ou que não apresentassem os Institutos Federais como locus da pesquisa.

Ainda sobre os critérios de exclusão, as dissertações ou teses que tratassem do EMI em escolas estaduais ou que, mesmo com locus nos IFs, abordassem o Programa Nacional de Integração da Educação Profissional com a Educação Básica na Modalidade de Educação de Jovens e Adultos (Proeja) também não foram incluídas, pois acreditamos que essa modalidade de ensino merece estudo aprofundado e exclusivo, considerando suas particularidades. Entendemos que o EMI e o Proeja não podem ser vistos pelas mesmas lentes, uma vez que cada modalidade apresenta suas especificidades.

O próximo passo foi a leitura detalhada de 13 textos, entre teses e dissertações, selecionados para a elaboração dos resultados e discussão, também numa abordagem qualitativa (GIL, 2008). Paralelamente, realizamos uma pesquisa na plataforma Lattes para traçar o perfil dos pesquisadores autores desses textos.

\section{PARA ONDE APONTAM AS PESQUISAS?}

A partir da busca na BDTD e aplicação dos critérios de inclusão e exclusão, chegamos ao quantitativo de oito dissertações e cinco teses, num total de 13 trabalhos, publicados entre 2012 e 2019. A seguir organizamos o Quadro 1, com informações básicas sobre os trabalhos que incluímos nesta pesquisa.

Quadro 1 - Trabalhos encontrados na busca na BDTD

\begin{tabular}{|c|c|c|c|c|}
\hline $\begin{array}{c}\text { Ano de } \\
\text { publicação }\end{array}$ & Título do trabalho & Autor(a) & Instituição & Tipo \\
\hline 2012 & $\begin{array}{c}\text { A possível integração curricular no } \\
\text { Instituto Federal de Educação, Ciência } \\
\text { e Tecnologia Baiano: análise do curso } \\
\text { técnico em agropecuária }\end{array}$ & $\begin{array}{c}\text { Helena Luiza } \\
\text { Oliveira Coura }\end{array}$ & UFBA & Dissertação \\
\hline 2012 & $\begin{array}{c}\text { A prática pedagógica na perspectiva } \\
\text { curricular do ensino médio integrado: } \\
\text { um estudo avaliativo }\end{array}$ & $\begin{array}{c}\text { Roseany Carla } \\
\text { Dantas de Menezes }\end{array}$ & UFC & Dissertação \\
\hline $\begin{array}{c}\text { Políticas e planejamento do ensino } \\
\text { médio (integrado ao técnico) e } \\
\text { da língua estrangeira (inglês): na } \\
\text { mira(gem) da politecnia e da integração }\end{array}$ & $\begin{array}{c}\text { Daniella de Souza } \\
\text { Bezerra }\end{array}$ & USP & Tese \\
\hline
\end{tabular}




\begin{tabular}{|c|c|c|c|c|}
\hline 2013 & $\begin{array}{c}\text { Concepção de integração curricular } \\
\text { presente nos cursos de ensino médio } \\
\text { integrado em agropecuária do Instituto } \\
\text { Federal Catarinense }\end{array}$ & $\begin{array}{c}\text { Rosângela de } \\
\text { Amorim Teixeira de } \\
\text { Oliveira }\end{array}$ & UFSC & Dissertação \\
\hline 2013 & $\begin{array}{l}\text { Desatando os nós do currículo } \\
\text { integrado no ensino médio no âmbito } \\
\text { dos institutos federais }\end{array}$ & $\begin{array}{l}\text { Marcia Maria Brisch } \\
\text { Schneider }\end{array}$ & Unijuí & Dissertação \\
\hline 2013 & $\begin{array}{c}\text { A concepção de integração contida } \\
\text { no decreto 5.154/2004 e suas } \\
\text { repercussões na prática docente: um } \\
\text { estudo sobre o ensino médio integrado } \\
\text { do Instituto Federal do Tocantins }\end{array}$ & $\begin{array}{c}\text { Saldanha Alves } \\
\text { Braga }\end{array}$ & UNB & Dissertação \\
\hline 2015 & $\begin{array}{c}\text { Em busca da integração: a } \\
\text { re(construção) dos saberes históricos } \\
\text { e os fundamentos de uma proposta de } \\
\text { Ensino Médio Integrado no IFPB (2004- } \\
\text { 2006) }\end{array}$ & $\begin{array}{l}\text { Stênio Farias D'Avila } \\
\text { Lins }\end{array}$ & UFPB & Dissertação \\
\hline 2016 & $\begin{array}{c}\text { A Educação Física no currículo integrado } \\
\text { do IFBA: realidade e possibilidades }\end{array}$ & $\begin{array}{l}\text { Rosicler Teresinha } \\
\text { Sauer Santos }\end{array}$ & UFBA & Tese \\
\hline 2017 & \begin{tabular}{|l|} 
Uma análise da integração curricular no \\
IFS/Campus Aracaju: sua constituição \\
e os seus efeitos sobre o ensino de \\
matemática no curso de eletrotécnica \\
\end{tabular} & $\begin{array}{l}\text { Shirleyde Dias do } \\
\text { Nascimento }\end{array}$ & UFS & Dissertação \\
\hline 2018 & $\begin{array}{c}\text { A integração do ensino médio à } \\
\text { educação profissional técnica de nível } \\
\text { médio no curso técnico em edificações } \\
\text { - IFES Campus Colatina }\end{array}$ & $\begin{array}{l}\text { Jaqueline Ferreira } \\
\text { de Almeida }\end{array}$ & UFES & Dissertação \\
\hline 2018 & $\begin{array}{c}\text { Efetividade social e pedagógica do } \\
\text { ensino médio integrado: análise de } \\
\text { sua implantação no Instituto Federal } \\
\text { Goiano }\end{array}$ & Paulo Silva Melo & PUC_GO & Tese \\
\hline 2018 & $\begin{array}{c}\text { Currículos instituídos, atos de currículo } \\
\text { instituintes e transduções curriculares } \\
\text { no contexto dos cursos técnicos } \\
\text { integrados de nível médio do IFBA }\end{array}$ & $\begin{array}{l}\text { Diana Sampaio } \\
\text { Melo }\end{array}$ & UFBA & Tese \\
\hline 2019 & $\begin{array}{c}\text { Currículo do ensino médio integrado do } \\
\text { IFMG: a partitura, a polifonia e os solos } \\
\text { da educação física }\end{array}$ & Katia Regina de Sá & USP & Tese \\
\hline
\end{tabular}

Fonte: Elaborado pelas autoras com base nos dados da pesquisa.

Conforme observamos no Quadro 1, os primeiros trabalhos publicados e disponíveis na BDTD que encontramos em nossa busca são do ano de 2012, o que condiz com a cronologia esperada, uma vez que buscamos por trabalhos que tratassem da integração curricular no EMI dos Institutos Federais. Como sua criação data de 2008, seria incoerente encontrar resultados de anos anteriores a esse ou num intervalo posterior muito curto, considerando o tempo médio de conclusão de uma Pós-Graduação stricto sensu. Nessa discussão, destacamos a tese de Daniella de Souza Bezerra, publicada em 2012. Levando em conta o tempo necessário para a construção e finalização de um trabalho de conclusão de Doutorado, a autora foi bastante desbravadora em sua pesquisa, abordando um tema extremamente recente. 
Em relação aos autores das pesquisas, é relevante destacar quem são esses sujeitos pesquisadores e tentar entender, de certa forma, a motivação dos estudos realizados. Ao analisarmos os currículos Lattes dos autores, destacamos a formação inicial desses sujeitos, a instituição na qual possuem vínculo empregatício atual e o cargo ocupado, conforme observamos no Quadro 2, a seguir.

Quadro 2 - Perfil dos pesquisadores

\begin{tabular}{|c|c|c|c|}
\hline Autor(a) & Instituição & Graduação & Cargo \\
\hline Helena Luiza Oliveira Coura & IFBA & Pedagogia & Pedagoga \\
\hline Roseany Carla Dantas de Menezes & IFPA & Educação Física & $\begin{array}{c}\text { Técnica } \\
\text { Administrativa }\end{array}$ \\
\hline Daniella de Souza Bezerra & IFG & $\begin{array}{l}\text { Letras Português/ } \\
\text { Inglês }\end{array}$ & Docente \\
\hline $\begin{array}{l}\text { Rosângela de Amorim Teixeira de } \\
\text { Oliveira }\end{array}$ & IFC & Pedagogia & Pedagoga \\
\hline Marcia Maria Brisch Schneider ${ }^{5}$ & IFFar & Pedagogia & Pedagoga \\
\hline Saldanha Alves Braga & IFTO & Filosofia & Docente \\
\hline Stênio Farias D’Avila Lins & IFPB & História & Docente \\
\hline Rosicler Teresinha Sauer Santos & IFBA & Educação Física & Docente \\
\hline Shirleyde Dias do Nascimento & IFSE & Pedagogia & Pedagoga \\
\hline Jaqueline Ferreira de Almeida & UFES & Pedagogia & $\begin{array}{c}\text { Técnica } \\
\text { Administrativa }\end{array}$ \\
\hline Paulo Silva Melo & IFGoiano & Física & Docente \\
\hline Diana Sampaio Melo & IFBA & Pedagogia & Pedagoga \\
\hline Katia Regina de Sá & IFMG & Educação Física & Docente \\
\hline
\end{tabular}

Fonte: Elaborado pelas autoras com base nos dados da pesquisa.

Conforme observamos no Quadro 2, os autores dos trabalhos são servidores da rede dos Institutos Federais, com exceção apenas da autora Jaqueline Ferreira de Almeida, que é Técnica Administrativa em Educação (TAE) na Universidade Federal do Espírito Santo (Ufes). No que diz respeito à formação desses sujeitos, boa parte deles (6) possui

O Lattes da autora não traz a informação sobre seu vínculo com o IF, no entanto, em busca feita no Diário Oficial da União (DOU), identificamos sua nomeação como pedagoga no Instituto Federal Farroupilha (IFFar). 
Graduação em Pedagogia. Os demais possuem cursos de Licenciatura ou Bacharelado, com destaque para a área de Educação Física, com 3 ocorrências. Essa configuração parece-nos mostrar que a temática ainda é bastante restrita a pesquisadores de áreas específicas, no entanto entendemos que deveria ser de amplo interesse, rompendo a clássica divisão entre as áreas de humanas e exatas e seus tradicionais objetos de pesquisa.

O cargo ocupado por esses pesquisadores nas respectivas instituições é majoritariamente o cargo de docência ( 6 ocorrências) e, em seguida, o de pedagoga (5 ocorrências). As outras duas autoras são TAEs em IFs. É interessante destacar, ainda sobre o perfil dos autores dos textos analisados nesta pesquisa, a presença do Instituto Federal da Bahia (Ifba). Entre os 13 trabalhos incluídos neste estudo, 3 são de autoria de servidores do Ifba, o que pode revelar indícios de uma preocupação prioritária nesse instituto.

Considerando os resultados encontrados em nossa busca na plataforma Lattes, o perfil dos pesquisadores aponta para uma congruência com o tema em questão, uma vez que o currículo integrado é uma necessidade e deveria ser uma realidade em todos os cursos de EMI ofertados em IFs. A preocupação com questões de tanta relevância, como a integração curricular, no âmbito dessa rede de educação, advinda de pesquisadores que ocupam majoritariamente cargos em IFs, indicam um ponto positivo para a educação profissional e tecnológica: apesar de não haver ainda um cenário ideal daquilo que se espera do EMI dos IFs, há uma inquietação e uma busca para a contribuição e melhoria da prática educacional nesse contexto, abrangendo inclusive as cinco regiões do Brasil.

Assim, após sucinta análise dos trabalhos encontrados e do perfil de seus respectivos autores, passaremos a discutir as teses e dissertações e suas contribuições para a questão da integração curricular no EMI dos Institutos Federais, bem como os desafios postos e os caminhos a serem percorridos.

O primeiro trabalho analisado foi a dissertação de Coura (2012), que analisa e discute em que medida a integração curricular se faz presente no IFBaiano, tendo o Curso Técnico em Agropecuária Integrado do Campus Catu como objeto de estudo. A pesquisa se caracterizou como estudo de caso, do tipo exploratória e analítica. Para conseguir alcançar seu objetivo, a autora investigou o Projeto Pedagógico de Curso (PPC), analisando se havia planejamento compartilhado entre os professores e se havia coerência entre teoria e prática, no que diz respeito à compreensão dos professores sobre o tema da integração curricular.

Como resultados, Coura (2012) apresenta a conclusão de que a integração curricular da forma como a autora entende que deveria ser feita - numa perspectiva integradora entre trabalho, ciência e cultura, com a proposta de formação omnilateral e politécnica - não ocorre no curso analisado. O que mais se constatou na pesquisa foi a visão de integração entre curso técnico e Ensino Médio no sentido de este servir como subsídio para a compreensão das disciplinas da formação profissional. Percebeu-se também a ausência do planejamento compartilhado entre professores, além de o PPC estudado não orientar o sentido da integração do currículo, uma vez que não apresenta nenhuma proposta de atividade integradora ou metodologias para esse fim. 
Também publicado em 2012, a pesquisa de Menezes (2012) teve caráter qualitativo e seguiu uma abordagem fenomenológica, com o uso de entrevistas reflexivas, para investigar se a prática docente no curso Técnico em Agropecuária Integrado ao Ensino Médio do Instituto Federal do Pará, Campus Castanhal, era condizente com os pressupostos legais - Decreto 5.154/2004 e o Documento Base para o Ensino Médio Integrado. $O$ estudo revelou que não há uma integração efetiva na prática docente. O que acontece, de fato, é um ensino fragmentado em disciplinas isoladas e não organizada por eixos, conforme o que é proposto nos mecanismos legais mencionados anteriormente.

Menezes (2012), em sua pesquisa, conseguiu levantar ainda alguns entraves, que, de acordo com os professores entrevistados, dificultam a concretização da integração do currículo, sendo eles a (falta de) formação inicial e continuada para o ensino integrado; o acúmulo de atividades administrativas e uma carga horária elevada em diferentes níveis de ensino. O máximo que se percebe no curso pesquisado são ações isoladas organizadas por alguns poucos professores, numa tentativa de agir em conjunto.

No terceiro trabalho encontrado, seguindo a ordem cronológica de publicação, Bezerra (2012) apresenta sua tese de Doutorado com o objetivo de analisar, de forma qualiquantitativa, 62 matrizes curriculares, 22 planos de curso e 14 ementários, catalogados em sites de IFs. A pesquisa pretendeu analisar os documentos supracitados a fim de identificar se o que é previsto e almejado, tanto para o Ensino Médio Integrado à Educação Profissional Técnica (EMIEPT) quanto para o ensino do Componente Curricular Língua Estrangeira-Inglês (CCLEI), é identificado nos documentos analisados.

A pesquisa de Bezerra (2012) revelou que a maioria dos planos investigados não incorpora objetivos de organização curricular que aponte para a formação integrada e politécnica - formação geral integrada à formação técnica. Da mesma forma, o ensino do CCLEI mostrou-se ainda influenciado por tradições do ensino de idiomas no país, numa abordagem estrutural, comunicativa e instrumental, furtando-se, majoritariamente, ao cumprimento dos objetivos de formação humana integral, que deveria ser parte de todas as disciplinas do EMIEPT. Bezerra (2012) identificou ainda que a formação que integre realmente a formação geral e a profissional não é facilmente encontrada, mesmo no âmbito do planejamento, visto que o perfil dos egressos dos cursos EMIEPT previsto nos planos analisados é predominantemente profissional. As sinalizações encontradas na pesquisa são de justaposição de disciplinas, inclusive com a repetição de conteúdo em mais de uma unidade curricular.

Para finalizar, Bezerra (2012) alerta que, se os IFs estão de fato comprometidos em escamotear a dualidade escolar hegemônica no Brasil - que divide a sociedade em classes e forma, separadamente, mão de obra para o mercado e líderes - será necessário empreender grande esforço, do ponto de vista de formação continuada dos professores e equipe pedagógica, para melhor compreensão e planejamento da integração curricular e interdisciplinaridade.

Em seu trabalho de conclusão de Mestrado, Oliveira (2013) objetivou compreender qual era a concepção de currículo integrado que fundamentava a proposta de formação dos cursos de Ensino Médio Integrado em Agropecuária do Instituto Federal Catarinense (IFC). A pesquisa apontou que a discussão sobre a articulação entre Ensino 
Médio e educação profissional é um desafio para a superação da dualidade historicamente construída na educação brasileira. $O$ estudo revelou ainda que as diretrizes oficiais sobre a integração curricular e a sua materialização não apontam para o mesmo caminho. Além disso, percebeu-se que a proposta do curso analisado no IFC está em processo de amadurecimento teórico-metodológico e, portanto, apresenta limitações em sua efetivação.

Vários foram os problemas levantados pelos entrevistados em relação à materialização de atividades integradoras: desconhecimento teórico e metodológico sobre a integração; rivalidade entre professores das disciplinas de formação geral e os de formação técnica; a formação tradicional que os docentes receberam em seus cursos de Graduação; dificuldade em romper com algo já arraigado na comunidade acadêmica em que estão inseridos; necessidade de contratação de mais pessoal; a não priorização do diálogo por parte da gestão escolar; interferência dos conselhos profissionais; obrigatoriedade de cumprimento de uma ementa posta e o distanciamento e/ou diferenças pessoais entre professores.

Apesar das contradições encontradas em sua pesquisa, Oliveira (2013) pôde identificar que, embora havendo limitações reais, o curso em estudo desenvolve uma série de ações pedagógicas integradoras. Um exemplo dado por um dos professores entrevistados foi uma visita técnica a um aterro sanitário, que envolveu o trabalho de docentes de diferentes áreas, como Biologia, Agroecologia, Gestão e Cooperativismo e Geografia.

Durante as entrevistas outros professores também reconheceram a necessidade de se compreender mais sobre a integração e de colocá-la em prática. A formação continuada foi citada como algo considerado crucial pelos profissionais envolvidos nessas atividades, com vistas ao seu fortalecimento.

Schneider (2013), em sua dissertação, apresenta como propósito da pesquisa discutir sobre o que já foi feito e o que ainda está por fazer no sentido da integração entre a formação geral e a profissional, tendo como objeto de estudo o Currículo Integrado no Ensino Médio e Técnico no Instituto Federal Farroupilha (IFFar) Campus Santo Augusto. Trata-se de uma pesquisa documental, fundamentada na análise textual discursiva.

Sua pesquisa revelou que, sobre a questão da integração curricular, existe uma dicotomia presente na lei e, consequentemente, na prática. A autora refere-se à dualidade que é possível encontrar em documentos legais que regem a educação, pois,

enquanto a LDB enfatiza a finalidade do Ensino Médio como a formação para a vida, o Decreto vem determinar a independência do ensino técnico em relação ao Ensino Médio. Neste caso, a educação profissional de nível técnico passa a ter uma organização curricular própria, independente do Ensino Médio, podendo ser oferecida de modo concomitante ou sequencial. A impressão gerada nessa dualidade é que o Ensino Médio prepara para a vida e o técnico para o trabalho, como se estes pudessem representar situações diferentes e um não fizesse parte do outro ( $\mathrm{SCH}$ NEIDER, 2013, p. 64).

Isso posto, a autora conclui que é necessário um estudo sobre a educação e a cultura, uma vez que "a integração implica a contextualização do conhecimento de todas as áreas no mundo do trabalho no contexto da cultura" (SCHNEIDER, 2013, p. 107). 
Ainda do ano de 2013, a dissertação de Braga investiga a prática docente do Instituto Federal do Tocantins (Ifto) Campus Paraíso. O que se pretendeu foi confrontar a concepção de integração presente no Decreto 5.154/2004 com a sua materialização na prática docente do Campus analisado. $\mathrm{O}$ autor fez uso de questionários e entrevistas semiestruturadas com os professores, além de uma pesquisa documental, tratando-se de uma pesquisa de abordagem qualitativa, cujos dados foram analisados pela proposta de Bardin.

Braga (2013) chegou a resultados que apontam para uma incongruência entre a concepção de integração curricular esperada, no âmbito do EMI, e a realidade encontrada no Ifto Campus Paraíso. Não se identificou, na instituição pesquisada, uma ação integradora que seja considerada suficiente para se falar em currículo de formação geral integrado ao currículo de formação técnica. O que se percebeu foi uma visão simplista, da maior parte dos participantes da pesquisa, sobre a integração, como sendo uma justaposição de disciplinas a partir de um tema comum.

No item que Braga (2013) denomina Recomendações, o autor conclui seu estudo sugerindo três ações: 1) política de formação inicial e continuada para os professores dos IFs, com vistas à integração curricular sob os eixos Trabalho, Ciência e Cultura; 2) direcionamento da percepção docente sobre a integração no EMI, visando a esclarecer a diferença entre a simples percepção da importância dessa ação e sua materialização na prática; 3) formação político-ético-social sobre a formação integral no nível médio.

A próxima publicação resultante da pesquisa foi o trabalho de dissertação de Stênio Farias D'Avila Lins, de 2015. O estudo analisou o processo de formulação do PPC do Instituto Federal da Paraíba (IFPB), Campus João Pessoa, com base nos saberes históricos identificados em sua construção, a partir de análise de documentos e entrevistas. O estudo foi motivado por questionamentos do tipo "Para que serve estudar História? Qual a função do conhecimento histórico na Educação Básica?" (LINS, 2015, p. 225). Essas questões, de acordo com o próprio autor do texto, foram até agora minimante respondidas.

De acordo com o exposto em sua pesquisa, Lins (2015) afirma que a rearticulação entre educação profissional e o Ensino Médio permitida pelo Decreto 5.154/2004 - antes separados pelo Decreto 2.208/1997 - não veio acompanhada de uma metodologia ou de caminhos para que essa integração se efetivasse, ficando os IFs com essa responsabilidade.

A partir dessa realidade, o IFPB Campus João Pessoa passa a ofertar o EMI, como uma proposta de formar tanto para a cidadania quanto para o trabalho produtivo. Lins (2015) buscou encontrar, na prática dos professores de História no EMI do Campus em estudo, atividades interdisciplinares que dialogassem com a habilitação profissional de cada curso. $O$ que foi encontrado nos planos de ensino analisados, no entanto, foi uma formação voltada para a preparação dos alunos para o Exame Nacional do Ensino Médio (Enem), adotado pela maioria das universidades em seu processo de seleção.

A segunda tese identificada na busca realizada nessa pesquisa foi publicada em 2016, pela Universidade Federal da Bahia (Ufba). Em seu trabalho, Santos (2016) fez uma pesquisa qualitativa, na tentativa de compreender e analisar as contradições, os limites e as possibilidades do currículo integrado, no que diz respeito ao ensino da Edu- 
cação Física no Instituto Federal da Bahia (Ifba). Foram colhidos depoimentos a partir da gravação e transcrição do 10 Encontro de Professores de Educação Física do Ifba. Ainda, o documento resultante desse grupo de trabalho, que tratou da proposta curricular da Educação Física no Ifba, e o Projeto Pedagógico Institucional (PPI) do Ifba foram analisados no estudo.

Como afirma Santos (2016), de maneira geral os relatos dos participantes do encontro apontam que ainda há um longo percurso para o que está posto no PPI e as condições concretas para sua instalação. Muitos professores presentes no evento, que serviu de corpus para a pesquisa, "estavam mais preocupados com a sistematização" (SANTOS, 2016 p. 170) de atividades e jogos do que com as questões relativas ao currículo da Educação Física, para a elaboração do currículo integrado.

Um ponto positivo destacado sobre o evento analisado na investigação foi a inclusão, na proposta de currículo elaborada no Encontro, de estratégias para a integração curricular, como projetos integradores, seminários e fóruns de discussões, jogos e festivais integradores, visitas de campo, etc. Como essas ações se fizeram presentes em caráter de planejamento, ainda há muito a trabalhar para sua efetivação.

O próximo trabalho analisado foi a dissertação de Shirleyde Dias do Nascimento, do ano de 2017, que teve o objetivo de analisar como ocorre a integração curricular e como se efetiva o ensino de Matemática no curso Técnico de Nível Médio Integrado em Eletrotécnica do Instituto Federal de Sergipe (IFS) Campus Aracaju. Foi feita uma análise documental, por meio da leitura e estudo do PPC do curso em questão, além de entrevistas semiestruturadas com os docentes e grupos focais formados por alunos.

A pesquisa mostrou a ausência da integração entre as disciplinas, havendo aquelas que preparam os alunos para o Enem e as de formação profissional. Sobre o ensino de Matemática, revelou-se que este está mais voltado para a formação geral do Ensino Médio, não havendo relação com as disciplinas técnicas. No que se refere à organização da disciplina, a pesquisa apontou que há somente uma variação da distribuição dos conteúdos entre os anos letivos, para subsidiar o ensino das disciplinas técnicas, não havendo grande destaque em comparação com os cursos médios regulares.

Os dados obtidos a partir das entrevistas revelaram a ausência de planejamento que dê um direcionamento para a ligação entre as várias áreas do conhecimento, havendo raras referências a ações "que promovam relações entre as disciplinas, sendo evidente ações fragmentadas, dentro de um escopo disciplinar" (NASCIMENTO, 2017, p. 145).

A última dissertação encontrada, pela ordem cronológica dos resultados, publicada em 2018, faz uma análise do curso Técnico Integrado em Edificações do Instituto Federal do Espírito Santo (Ifes), Campus Colatina. Na pesquisa, sob a ótica marxista de formação humana integral, Almeida (2018) analisou o PPC do curso de Edificações, o Plano de Desenvolvimento Institucional (PDI), o Regulamento de Organização Didática (ROD) e relatórios de gestão do campus. Além disso, foram aplicados questionários e entrevistas com alunos, cinco professores e gestores do curso. 
Foram identificados, a partir do estudo de Almeida (2018), limites para a concretização da integração, sobretudo a expansão e a verticalização do Ifes, que acarretam consequências diretas na oferta de cursos integrados. Outro desafio é a organização curricular que, ao invés de apresentar a integração do currículo, está pautada na justaposição de disciplinas, sobrecarregando os alunos, na medida em que se eleva também a quantidade de avaliações e atividades, relativas a cada unidade curricular.

Foi percebido também por Almeida (2018) a priorização das disciplinas de formação geral, constatada pelo maior tempo dedicado a este núcleo, assim como a quantidade de aulas reservadas para a formação geral dentro do currículo, nos três primeiros anos no EMI. No quarto ano do curso, contudo, há um foco maior nas disciplinas de formação técnica, o que caracteriza o processo de justaposição mencionado anteriormente. A ausência da real integração do currículo esbarra, de acordo com a pesquisa, no desconhecimento dos sujeitos envolvidos acerca do Ensino Médio Integrado, além da barreira física encontrada entre os professores do núcleo propedêutico e os do núcleo técnico.

Ainda no ano de 2018, a tese de Melo teve como objeto o EMI do Instituto Federal Goiano (IFGoiano), identificando suas contradições em relação à formação integral, unitária e politécnica dos estudantes. Realizou-se uma pesquisa qualitativa, com pesquisa documental e de campo, a fim de desvelar a efetividade (ou não) da superação da formação humana e da formação técnica no EMI dos campi Hidrolândia, Iporá, Morrinhos e Trindade.

A partir da pesquisa, foram encontrados problemas "na formação pedagógica dos professores, nas condições reais de promoção da integração curricular, na rigidez epistemológica" (MELO, 2018, p. 10) de alguns professores, que preferem o currículo disciplinar ao currículo integrado. Por fim, Melo (2018) aponta para a necessidade de esclarecimentos sobre a função do EMI e da integração curricular.

Na última tese identificada na busca na BDTD, Sá (2019) estudou o currículo do EMI do Instituto Federal de Minas Gerais (IFMG), suas relações com e educação de tempo integral e a construção da disciplina Educação Física. Os dados obtidos, por meio de análise de documentos, grupo focal e entrevistas narrativas, mostram um currículo permeado do discurso neoliberal para atender ao mercado de trabalho. Revelam também a inexistência da integração curricular, que resulta num excesso de disciplinas que sobrecarregam os estudantes com provas e atividades. Os PPCs analisados pela autora mostraram que há a justaposição de componentes curriculares, em detrimento da integração das disciplinas de formação geral e as de formação técnica, o que acarreta uma elevada carga horária aos estudantes. Sobre essa questão, a autora defende um rearranjo da proposta formativa do IFMG, para que se respeite os tempos e os ritmos dos jovens estudantes, dando-lhes tempo livre para usufruírem das diversas oportunidades oferecidas pelo Instituto, como experiências diferenciadas de ensino, pesquisa e extensão.

Em seu trabalho, Sá (2019) conclui que o currículo prescrito do IFMG é transposto pelo discurso neoliberal, com fins mercadológicos, indicando a necessidade de investimento institucional, na tentativa de produzir um currículo integrado. Em sua análise, a 
autora destaca um campus, que ela denomina Campus 2, por ter sido privilegiado com a criação de um currículo em condições de coletividade, que lhe conferiu um caráter mais integrador, diferenciando-se dos demais.

Pelas análises realizadas, percebemos que são vários os desafios impostos pela realidade das escolas brasileiras, mais especificamente pela realidade dos IFs. Assim sendo, os limites objetivos deveriam instigar a ressignificação de procedimentos, se o que se pretende é realmente a emancipação social e a promoção da autonomia dos sujeitos (ARAÚJO, 2014). Um dos maiores desafios percebidos nos trabalhos analisados é a dicotomia encontrada entre a teoria e a prática e a separação entre formação geral e formação profissional.

Sobre as visões dicotômicas supracitadas, Araújo (2014) afirma que isso se desdobra na separação das disciplinas teóricas e práticas, demarcando respectivamente os saberes e conhecimentos que desenvolveriam o pensar e aqueles que priorizariam o fazer. A fim de romper com essa lógica dualista, deveria haver a articulação entre teoria e prática, sob a ótica da unidade indissolúvel de Candau (1995 apud ARAÚJO, 2014). Na perspectiva de unidade, a teoria "nega a prática imediata para revelá-la como práxis social, a prática nega a teoria como um saber autônomo, como puro movimento de ideias" (ARAÚJO, 2014, p. 106). Esse deveria ser o pensamento sobre teoria e prática em orientação dos projetos de ensino integrado.

Ainda segundo o autor, procedimentos de ensino, como jogos, seminários, oficinas, aulas expositivas, visitas técnicas, entre outros, podem servir ou não para o desenvolvimento de práticas integradoras. A simples escolha de um ou outro procedimento metodológico não é o que irá determinar se a prática pedagógica será ou não de viés tradicional, mecanicista, utilitário ou se servirá como prática libertária, crítica, comprometida com o desenvolvimento das amplas capacidades humanas, numa formação humana integral (ARAÚJO, 2014).

Isso posto, o foco nos arranjos curriculares presente na maior parte das teses e dissertações estudadas neste trabalho pode apontar para uma tendência dos próprios pesquisadores de assumir que desenhos metodológicos podem determinar ou não a prática integradora. Consideramos de extrema importância a existência de documentos oficiais e institucionais que prevejam a prática integradora, mas parece ser a atitude docente integradora um dos fatores mais decisivos para a real integração curricular, uma vez que "supõe um compromisso com a transformação social e a recusa à lógica pragmática" (ARAÚJO, 2014, p. 119).

\section{CONSIDERAÇÕES FINAIS}

Este trabalho propôs uma pesquisa do tipo estado da arte, com o objetivo de entender as concepções de integração curricular em teses e dissertações, com foco no EMI dos IFs. Os textos analisados permitiram entender que os estudos sobre a integração curricular no âmbito do EMI dos IFs, encontrados nas teses e dissertações, esbarram em questões similares: o distanciamento do que se quer daquilo que se faz. Majoritariamente, os trabalhos apontam para currículos que não trazem caminhos para a integração curricular. A prática docente, na maioria dos casos analisados, acontece de forma individualizada dentro de suas respectivas disciplinas, numa visão tradicional 
(OLIVEIRA, 2013) de fragmentação (MENEZES, 2012) e justaposição curricular (BEZERRA, 2012; BRAGA, 2013; ALMEIDA, 2018), contrariando o que se espera do EMI e, muitas vezes, acarretando um excesso de disciplinas, atividades e provas para os alunos (SÁ, 2019; ALMEIDA, 2018).

Muito se falou sobre ações isoladas de alguns professores que apresentam mais afinidade e aproximação pessoal, na tentativa de desenvolver ações interdisciplinares, mas sem a solidificação necessária para serem consideradas suficientemente integradoras (MENEZES, 2012; OLIVEIRA, 2013). Outra discussão comum a muitos dos trabalhos analisados foi a necessidade de formação inicial e continuada de professores e equipe pedagógica, com subsídios para o planejamento e execução de um currículo, de fato, integrado (MENEZES, 2012; ALMEIDA, 2018; MELO, 2018; BEZERRA, 2012; SCHNEIDER, 2013; BRAGA, 2013).

De maneira geral, além do desconhecimento sobre a integração curricular, os autores mostraram outras limitações para a prática de um currículo integrado, como o acúmulo de atividades administrativas pelos professores; carga horária elevada; necessidade de contratação de pessoal; deturpação do foco do EMI, ora para a preparação para o Enem (LINS, 2015), ora para atender apenas ao mercado de trabalho; a verticalização do ensino nos IFs, que geram uma sobrecarga de trabalho para os docentes; limites físicos que impedem a aproximação dos envolvidos e até mesmo rivalidade entre professores de formação geral e professores de formação técnica.

Apresentando-se como um aspecto positivo nos resultados encontrados, o perfil dos autores das teses e dissertações analisadas revela que esses pesquisadores são majoritariamente servidores dos IFs. Entendemos que, sendo a investigação científica fruto de inquietações e questionamentos, é oportuno perceber que existe a preocupação em se buscar compreender, analisar e contribuir com a integração curricular no contexto analisado, mesmo que ainda estejamos distantes do cenário ideal para tal fim.

Num caráter conclusivo, as reflexões trazidas neste texto nos levam a pensar sobre o papel da escola numa sociedade dividida por classes. Nela, há a escola para a classe trabalhadora, que forma mão de obra para esse mercado, e a escola para os donos dos meios de produção, que educa para formar líderes e gestores. Na luta por uma sociedade mais justa, o trabalho precisa tomar um sentido educativo e a escola deve ser um espaço humanizador. Nesse sentido, o EMI dos IFs deve buscar atender a esses objetivos, por meio de um currículo que realmente integre a formação geral e cidadã e a formação profissional. Esse caminho não será garantido se houver somente uma integração prevista legalmente e nos planos de cursos, pois a simples escolha metodológica por si só não é sinônimo de efetivação do currículo integrado. Vimos que técnica e métodos considerados tradicionais, como a aula expositiva, por exemplo, pode servir tanto ao ensino fragmentado e isolado de disciplinas quanto a uma educação integradora para a formação de cidadãos críticos e engajados.

Considerando ainda a prescrição legal do currículo integrado, pelo Decreto 5.154/2004, é evidente a relevância desses estudos para o crescimento intelectual e pedagógico dos sujeitos envolvidos no EMI dos IFs. Apesar, no entanto, de apontarem necessidades e desafios, os trabalhos não sugerem alternativas concretas para a efetiva materialização da integração curricular. Dessa maneira, estudos que apontem caminhos 
para a concretização de um currículo integrado, com sugestões de atividades integradoras e os meios para se chegar até elas, poderão trazer certamente muita contribuição para a prática docente dos Institutos Federais.

\section{REFERÊNCIAS}

ALMEIDA, Jaqueline Ferreira de. A integração do Ensino Médio à Educação Profissional Técnica de nível médio no curso técnico em edificações - Ifes Campus Colatina. Orientador: Bernard Charlot. 2018. 165 f. Dissertação (Mestrado em Educação) - Programa de Pós-Graduação em Educação da Universidade Federal do Espírito Santo, Vitória, 2018. Disponível em: http://repositorio.ufes.br/handle/10/8620 Acesso em: 26 dez. 2019.

ARAÚJO, Ronaldo Marcos de Lima. Práticas pedagógicas e ensino integrado. Curitiba: Instituto Federal do Paraná, 2014. (Coleção formação pedagógica; v. 7).

BEZERRA, Daniella de Souza. Políticas e planejamento do Ensino Médio (integrado ao técnico) e da língua estrangeira (inglês): na mira(gem) da politecnia e da integração. Orientador: Vojislav Aleksandar Jovanovic. 2012. 204 f. Tese (Doutorado em Educação) - Faculdade de Educação, Universidade de São Paulo, São Paulo, 2012. DOI: 10.11606/T.48.2012.tde-05022013-105725. Disponível em: https://teses.usp.br/teses/ disponiveis/48/48134/tde-05022013-105725/en.php Acesso em: 26 dez. 2019.

BRAGA, Saldanha Alves. A concepção de integração contida no decreto 5.154/2004 e suas repercussões na prática docente: um estudo sobre o Ensino Médio integrado do Instituto Federal do Tocantins. Orientador: Olgamir Francisco de Carvalho Netto. 2013. 131 f. Dissertação (Mestrado em Políticas Públicas e Gestão da Educação Profissional e Tecnológica) - Faculdade de Educação, Universidade de Brasília, Brasília, 2013. Disponível em: https://repositorio.unb.br/handle/10482/15080 Acesso em: 26 dez. 2019.

BRASIL. Ministério da Educação. Lei no 11.892 de 29 de dezembro de 2008. Institui a Rede Federal de Educação Profissional, Científica e Tecnológica, cria os Institutos Federais de Educação, Ciência e Tecnologia, e dá outras providências. Diário Oficial da República Federativa do Brasil, Brasília, 2008. Disponível em: http://www.planalto.gov.br/ccivil_03/_Ato2007-2010/2008/Lei/L11892.htm. Acesso em: 2 jan. 2020.

BRASIL. Ministério da Educação. Resolução no 6, de 20 de setembro de 2012. Define diretrizes curriculares nacionais para educação profissional técnica de nível médio. Brasília, DF: Ministério da Educação, 2012. Disponível em: http://portal.mec.gov.br/index.php?option=com_docman\&view=download\&alias=11663-rceb006-12-pdf\&category_slug=setembro-2012-pdf\&Itemid=30192. Acesso em: 20 out. 2019.

CIAVATTA, Maria. O ensino integrado, a politecnia e a educação omnilateral. Por que lutamos? Revista Trabalho \& Educação, v. 23, n.1, jan./abr. 2014. Disponível em: https://periodicos.ufmg.br/index.php/trabedu/article/view/9303. Acesso em: 2 jan. 2020.

CONSELHO NACIONAL DE DESENVOLVIMENTO CIENTÍFICO E TECNOLÓGICO. Currículo do sistema currículo Lattes. Disponível em: http://buscatextual.cnpq.br/buscatextual/busca.do?metodo=apresentar. Acesso em: 2 jan. 2020.

COURA, Helena Luiza Oliveira. A possível integração curricular no Instituto Federal de Educação, Ciência e Tecnologia Baiano: análise do curso técnico em agropecuária. Orientadora: Maria Regina Filgueiras Antoniazzi. 2012. 161 f. Dissertação (Mestrado em Educação) - Faculdade de Educação, Universidade Federal da Bahia, Bahia, 2012. Disponível em: http://repositorio.ufba.br/ri/handle/ri/9268. Acesso em: 26 dez. 2019.

GIL, A. C. Métodos e técnicas de pesquisa social. 6. ed. São Paulo: Atlas, 2008.

LINS, Stênio Farias D’Avila. Em busca da integração: a re(construção) dos saberes históricos e os fundamentos de uma proposta de Ensino Médio Integrado no IFPB (2004-2006). Orientadora: Vilma de Lourdes Barbosa Melo. 2015. 256 f. Dissertação (Mestrado em História) - Centro de Ciências Humanas e Letras, Universidade Federal da Paraíba, João Pessoa, 2015. Disponível em: https://repositorio.ufpb.br/jspui/ handle/tede/8359. Acesso em: 26 dez. 2019.

MELO, Diana Sampaio. Currículos instituídos, atos de currículo instituintes e transduções curriculares no contexto dos cursos técnicos integrados de nível médio do IFBA. Orientador: Roberto Sidnei Macedo. 2018. 166 f. Tese (Doutorado em Educação) - Faculdade de Educação, Universidade Federal da Bahia, Salvador, 2018. Disponível em: http://repositorio.ufba.br/ri/handle/ri/27949. Acesso em: 26 dez. 2019. MELO, Paulo Silva. Efetividade social e pedagógica do Ensino Médio integrado: análise de sua implantação no Instituto Federal Goiano. Orientador: José Carlos Libâneo. 2018. 227 f. Tese (Doutorado em Educação) - Escola de Formação de Professores e Humanidades, Pontifícia Universidade Católica de Goiás, Goiânia, 2018. Disponível em: http://tede2.pucgoias.edu.br:8080/handle/tede/4067. Acesso em: 26 dez. 2019. 
MENEZES, Roseany Carla Dantas de. A prática pedagógica na perspectiva curricular do Ensino Médio integrado: um estudo avaliativo. Orientadora: Patrícia Helena Carvalho Holanda. 2012. 114 f. Dissertação (Mestrado em Educação) - Faculdade de Educação, Universidade Federal do Ceará, Fortaleza, 2012. Disponível em: http://www.repositorio.ufc.br/handle/riufc/7353. Acesso em: 26 dez. 2019.

MINISTÉRIO DA EDUCAÇÃO. Instituto Federal de Educação, Ciência e Tecnologia Farroupilha/Campus São Vicente do Sul. Portarias de 4 de março de 2009. Diário Oficial da União: seção 2, Brasília, DF, ed. 49, n. 85, p. 16, 13 de março de 2009. Disponível em: http://www.in.gov.br/web/dou/-/portarias-de-4-de-marco-de-2009-172169650. Acesso em: 2 jan. 2020.

MOURA, D. H. A Organização curricular do Ensino Médio integrado a partir do eixo estruturante: trabalho, ciência, tecnologia e cultura. Revista Labor, Fortaleza, v. 1, n. 7, 2012. ISSN 1983-5000. Disponível em: http://www.periodicos.ufc.br/labor/article/view/6702. Acesso em: 2 jan. 2020.

MOURA, D. H. Ensino Médio integrado: subsunção aos interesses do capital ou travessia para a formação humana integral? Educação e Pesquisa, São Paulo, v. 39, n. 3, p. 705-720, jul./set. 2013. ISSN 1678-4632. Disponível em: http://www.scielo.br/scielo.php?script=sci_issuetoc\&pi$\mathrm{d}=1517-970220130003 \&$ Ing=pt\&nrm=iso. Acesso em: 2 jan. 2020.

NASCIMENTO, Shirleyde Dias do. Uma análise da integração curricular no IFS/Campus Aracaju: sua constituição e os seus efeitos sobre o ensino de matemática no curso de eletrotécnica. Orientador: Bernard Charlot. 2017. 165 f. Dissertação (Mestrado em Ensino de Ciências e Matemática) - Programa de Pós-Graduação em Ensino de Ciências e Matemática da Universidade Federal de Sergipe, São Cristóvão, 2017. Disponível em: http://ri.ufs.br/jspui/handle/riufs/5087. Acesso em: 26 dez. 2019.

NOSELLA, P. Trabalho e perspectivas de formação dos trabalhadores: para além da formação politécnica. Revista Brasileira de Educação, v. 12, n. 34, 2007. ISSN 14132478. Disponível em: https://www.researchgate.net/publication/26463368_Trabalho_e_perspectivas_de_formacao_dos_trabalhadores_para_ alem_da_formacao_politecnica. Acesso em: 2 jan. 2020.

OLIVEIRA, Rosângela de Amorim Teixeira de. Concepção de integração curricular presente nos cursos de Ensino Médio integrado em agropecuária do Instituto Federal Catarinense. Orientador: Juares da SilvaThiesen. 2013. 183 f. Dissertação (Mestrado em Educação) - Centro de Ciências da Educação, Universidade Federal de Santa Catarina, Florianópolis, 2013. Disponível em: https://repositorio.ufsc.br/xmlui/ handle/123456789/123162. Acesso em: 26 dez. 2019.

SÁ, Katia Regina. Currículo do ensino médio integrado do IFMG: a partitura, a polifonia e os solos da educação física. Orientador: Marcos Garcia Neira. 2019. 259 f. Tese (Doutorado em Educação) - Faculdade de Educação, Universidade de São Paulo, São Paulo, 2019. DOI: 10.11606/T.48.2019.tde-23052019-172656. Disponível em: https://teses.usp.br/teses/disponiveis/48/48134/tde-23052019-172656/pt-br.php. Acesso em: 26 dez. 2019.

SANTOS, Rosicler Teresinha Sauer. A Educação Física no currículo integrado do IFBA: realidade e possibilidades. Orientadora: Maria Cecília de Paula Silva. 2016. 216 f. Tese (Doutorado em Educação) - Faculdade de Educação, Universidade Federal da Bahia, Salvador, 2016. Disponível em: https://repositorio.ufba.br/ ri/handle/ri/21075. Acesso em: 26 dez. 2019.

SCHNEIDER, Marcia Maria Brisch. Desatando os nós do currículo integrado no Ensino Médio no âmbito dos institutos federais. Orientador: Juares da Silva Thiesen. 2013. 114 f. Dissertação (Mestrado em Educação nas Ciências) - Departamento de Humanidades e Educação, Universidade Regional do Noroeste do Estado do Rio Grande do Sul, ljuí, 2013. Disponível em: http://bibliodigital.unijui.edu.br:8080/xmlui/ handle/123456789/1848. Acesso em: 26 dez. 2019. 